\title{
CARACTERIZAÇÃO MORFOLÓGICA DE FRUTOS E SEMENTES E DESENVOLVIMENTO PÓS-SEMINAL DE Tamarindus indica L. - LEGUMINOSAE: CAESALPINIOIDEAE ${ }^{1}$
}

\author{
Danielle Marie Macedo Sousa², Riselane de Lucena Alcântara Bruno ${ }^{3}$, Carina Seixas Maia Dornelas², \\ Edna Ursulino Alves ${ }^{3}$, Albericio Pereira de Andrade ${ }^{4}$ e Luciana Cordeiro do Nascimento ${ }^{3}$
}

\begin{abstract}
RESUMO - O tamarindeiro (Tamarindus indica L.) pertence à família Leguminosae e é uma árvore frutífera, nativa da África tropical, de onde se dispersou por todas as regiões tropicais do mundo. A caracterização morfológica de frutos e sementes é importante para identificação das espécies, bem como serve de base para estudos que visem a maiores conhecimentos ligados à germinação e vigor. Este trabalho teve por objetivo descrever a morfologia de frutos, sementes e plântulas, bem como caracterizar o processo germinativo de Tamarindus indica L. Para o estudo do fruto, foram observados tipo, cor, dimensões, textura e consistência do pericarpo e deiscência e número de sementes por fruto. Os aspectos observados nas sementes foram: cor, dimensões, textura e consistência dos tegumentos; e forma, borda, posição do hilo e de outras estruturas presentes e características do embrião. O estádio de plântula foi considerado quando os protófilos já estavam totalmente formados. Os elementos vegetativos descritos e ilustrados foram radícula, coleto, hipocótilo, cotilédones, epicótilo, protófilos e caule. O fruto de Tamarindus indica é um legume indeiscente medindo aproximadamente 7,3 a 9,2 cm e contendo de 1 a 11 sementes. O eixo embrionário encontra-se inserido nos cotilédones, sendo axial e invaginado. A germinação da semente é do tipo epígea. A plântula apresenta protófilos compostos de seis a nove pares de folíolos pequenos opostos e glabros.
\end{abstract}

Palavras-chave: Morfologia, Plântulas, Leguminosae e Árvore Frutífera.

\section{TAMARIND FRUIT AND SEED MORPHOLOGICAL CHARACTERIZATION AND POST-SEMINAL DEVELOPMENT LEGUMINOSAE: CAESALPINIOIDEAE}

\begin{abstract}
Tamarind (Tamarindus indica L.) is a fruit tree native of tropical Africa, belonging to the Leguminosae family and nowadays is spread along tropical regions of the world. Fruit and seed morphologic characterization is important for species identification and has been used in studies on seed germination and vigor. The main aim of this research work was to describe fruit, seed and seedlings morphology as well as characterizing its germination process. Fruit traits analyzed were type, color, dimensions, texture and consistency of pericarp, dehiscence and number of seeds for fruit. On the other hand, seed traits were scored as to color, dimensions, texture and consistency of the teguments, shape, edges, position of hilum and other structures and embryo characteristics. Seedlings were recorded when protophylls development had already been complete. Radicle, collect, hypocotyl, cotyledons, epicotyl and protophyll have been described and illustrated. T. indica presents an indehiscent fruit with dimensions around 7.3 and $9.2 \mathrm{~cm}$ and containing 1-11 seeds. The embryonic axle is axial and invagined and is inserted into cotyledons. Seed germination is an epigeal-type and seedlings present protophyll composites with 6 and 9 pairs of opposing and glabrous and small leaflets.
\end{abstract}

Key words: Morphology, Seedling, Leguminosae and fruitful tree

\footnotetext{
${ }^{1}$ Recebido em 30.09.2008 e aceito para publicação em 25.08.2010.

${ }^{2}$ Doutorado em andamento pela Universidade Federal da Paraíba, UFPB, Brasil. E-mail: <daniellemariem@yahoo.com.br>.

${ }^{3}$ Universidade Federal da Paraíba, UFPB, Brasil.

${ }^{4}$ Instituto Nacional do Semi-Árido, INSA, Brasil.
} 


\section{INTRODUÇÃO}

O tamarindeiro (Tamarindus indica L.) é uma árvore frutífera bastante decorativa, pertencente à família Leguminosae, podendo alcançar até $25 \mathrm{~m}$ de altura. Seu fruto é uma vagem alongada, com 5 a $15 \mathrm{~cm}$ de comprimento, com casca pardo-escura, lenhosa e quebradiça, contendo três a oito sementes envolvidas por uma polpa parda e ácida (DONADIO et al., 1988).

É uma espécie nativa da África tropical, de onde se dispersou por todas as regiões tropicais do mundo. No Brasil, as plantas foram introduzidas da Ásia, e mostram-se bem adaptadas e subespontâneas em vários estados. Atualmente é encontrada nas Regiões Norte, Nordeste, Sudeste e Centro-Oeste, em plantações não organizadas e dispersas, devido à pouca ou quase nenhuma atenção dada à cultura (SILVA et al., 2000).

Mesmo não sendo nativo do Nordeste, o tamarindeiro é considerado planta frutífera típica da região. É uma árvore economicamente importante que se desenvolve largamente em regiões tropicais e subtropicais, sendo uma cultura ideal para regiões semiáridas, especialmente em áreas com seca de até cinco a seis meses (SILVA et al., 2000).

Quando se observa o grande número de espécies de leguminosas, evidencia-se a existência de problemas taxonômicos e impasses filogenéticos, que a análise tradicional de órgãos vegetativos e florais é insuficiente para solucionar. Assim, faz-se necessário o estudo de frutos, sementes e plântulas não somente com propósitos taxonômicos, filogenéticos ou ecológicos, mas também como contribuições ao conhecimento dessas espécies, ressaltando a importância de se conhecerem os aspectos morfológicos da espécie em questão.

Os estudos morfológicos auxiliam na identificação botânica da espécie, na interpretação dos testes de laboratório e no reconhecimento da espécie em bancos de sementes do solo e em fase de plântulas em formações florestais, que contribuem para o estudo dos mecanismos de dispersão, sucessão e regeneração natural da espécie (MELO et al., 2004).

Lawrence (1973) e Cunha e Ferreira (2003) afirmaram que as diferenças entre as plantas, assim como as mudanças que possam ter em comum, são suscetíveis de avaliação em larga escala pelos caracteres morfológicos dos componentes estruturais dessas plantas, tendo o seu valor apreciado pela sua constância.
Uma grande quantidade de características taxonômicas e filogenéticas são fornecidas pelas sementes, sendo as de emprego taxonômico as mais superficiais, mas os caracteres internos são de maior interesse na classificação (SOUZA e OLIVEIRA, 2004). Tem relevante importância a presença ou ausência de endosperma, forma e posição do embrião e número e posição dos cotilédones (LAWRENCE, 1973). De acordo com Gunn (1972), tanto as características externas quanto as internas das sementes são pouco modificadas pelo ambiente, sendo, portanto, um critério bastante seguro para identificação.

A semente é o principal meio para a reprodução da maioria das espécies lenhosas, e suas características morfológicas externas são importantes para auxiliar na identificação da família, gênero e espécie, além de poder ajudar nos estudos de germinação e armazenamento e nos métodos de cultivo (OLIVEIRA et al., 2006).

O conhecimento da morfologia do fruto e das sementes se faz necessário devido à sua importância na identificação botânica (ARAÚJO et al., 2004). De acordo com Faria e Davide (1993) e Rodrigues e Tozzi (2007), o aspecto morfológico de frutos e sementes é importante fator na identificação das espécies e no estudo do mecanismo de dispersão e regeneração. Para Silva et al. (1993), as características das sementes são importantes não só por subsidiar a interpretação dos testes de germinação em laboratório, mas também pelo fato de poder ser usada tão seguramente quanto as demais características das plantas para se chegar à identificação taxonômica.

A identificação das plantas no estádio juvenil contribui para o melhor entendimento da biologia da espécie, amplia os estudos taxonômicos e auxilia em trabalhos de levantamento ecológico, nos aspectos de regeneração por sementes em condições naturais e na ocupação e estabelecimento ambiental da espécie (SALLES, 1987).

O reconhecimento de plantas, a partir de plântulas, é tarefa que dificilmente é completada, uma vez que os caracteres externos nos estádios iniciais de desenvolvimento podem ser diferentes daqueles observados no indivíduo adulto ou em plantas de espécies e gêneros afins. Normalmente, nesta fase os indivíduos apresentam semelhanças que dificultam a sua identificação. O estudo de 
plântulas e plantas é indispensável para a obtenção de dados relevantes aos estudos de regeneração natural (PINHEIRO et al., 1989).

Os objetivos deste trabalho foram descrever e ilustrar os aspectos morfológicos do fruto, da semente e do desenvolvimento pós-seminal de Tamarindus indica L.

\section{MATERIAL E MÉTODOS}

\subsection{Coleta dos frutos}

Os frutos de tamarindo foram coletados, em outubro de 2006, em árvores selecionadas de um pomar localizado na Escola Agrotécnica Federal de Sousa - EAFS, em São Gonçalo, no Município de Sousa, PB, na zona fisiográfica do sertão paraibano, a $220 \mathrm{~m}$ de altitude, com temperatura média anual de $28^{\circ} \mathrm{C}, 60 \%$ UR e insolação anual de 3.058 h/ano. De acordo com a classificação de Köppen, este é classificado em Bsh, semiárido quente.

A coleta foi realizada diretamente nas árvores, quando já apresentavam queda espontânea, ou seja, quando estavam no período de maturidade fisiológica, com auxílio de um podão e de uma lona plástica para recolher os frutos. Após a coleta, os frutos foram beneficiados, embalados em sacos de polietileno impermeáveis ( $1 \mathrm{~mm}$ ) e armazenados em câmara fria ( $\pm 5^{\circ} \mathrm{C}$ e $90 \%$ UR), no Laboratório de Análise de Sementes (LAS), do Departamento de Fitotecnia do Centro de Ciências Agrárias da Universidade Federal da Paraíba, Campus II, Areia, PB, onde permaneceram até o início do experimento.

No LAS, as amostras foram misturadas para compor uma única amostra média. Desta, uma subamostra, constituída de 100 frutos, foi tomada aleatoriamente para descrição morfológica. As sementes foram extraídas manualmente dos frutos, sendo a seguir colocadas para secar durante $24 \mathrm{~h}$ em local sombreado e ventilado. Posteriormente, as sementes visualmente sadias e bem formadas foram selecionadas, acondicionadas em sacos de polietileno e armazenadas em refrigerador, a uma temperatura média de $\pm 8{ }^{\circ} \mathrm{C}$ e $37 \%$ UR.

\subsection{Caracterização morfológica dos frutos}

Foram selecionados, aleatoriamente, 100 frutos sadios, inteiros, sem deformação, maduros ou em estádio final de maturação. Com o auxílio de um microscópio estereoscópico binocular foram observados detalhes externos e internos do pericarpo, referentes à textura, consistência, brilho e número de sementes por fruto. O procedimento metodológico e a terminologia empregada, assim como os parâmetros observados para as descrições, foram baseados nos trabalhos de Kuniyoshi (1983), Vidal e Vidal (1984), Feliciano (1989) e Chaves (1994).

\subsection{Caracterização morfológica das sementes}

No estudo da semente, foram observadas e descritas as suas características morfológicas externas (cor, textura e consistência dos tegumentos, forma e bordo, posição do hilo e da micrópila, rafe e outras estruturas presentes) e internas (embrião: cotilédones, eixo hipocótilo-radícula, plúmula e presença de endosperma). Para facilitar o estudo da morfologia interna, as sementes foram previamente hidratadas.

O procedimento metodológico e a terminologia empregada, assim como os parâmetros observados para as descrições, foram baseados nos trabalhos de Barroso (1978), Ferri (1978), Kuniyoshi (1983), Vidal e Vidal (1984), Rodrigues e Araki (1988), Feliciano (1989), Beltrati (1992), Figliolia (1993), Oliveira (1993) e Chaves (1994).

\subsection{Desenvolvimento pós-seminal}

Para descrição e ilustração da morfologia e do desenvolvimento da plântula, 100 sementes foram colocadas em bandejas de polietileno ( 32 x 25 x 2,5 cm) com substrato vermiculita, mantidas em condições ambientais até o término do processo germinativo.

Para as descrições foram tomadas as plântulas mais vigorosas e, entre estas, apenas uma foi utilizada para ilustração.

Os elementos vegetativos descritos e ilustrados para cada fase do desenvolvimento pós-seminal foram os sugeridos por Roderjan (1983): raiz, colo, hipocótilo, cotilédones, epicótilo e protófilos de primeira e segunda ordens. O método e os termos empregados estão de acordo com Vidal (1978), Gunn (1981), Kuniyoshi (1983), Roderjan (1983), Beltrati (1992) e Barroso (1999).

\section{RESULTADOS E DISCUSSÃO}

\subsection{Caracterização morfológica do fruto}

O fruto de T. indica L. é simples, seco, indeiscente, monocárpico, mono ou polispérmico, do tipo legume bacoide com epicarpo crustáceo, tendo o pedúnculo preso na base; ápice apiculado e perfurante (Figura1). 

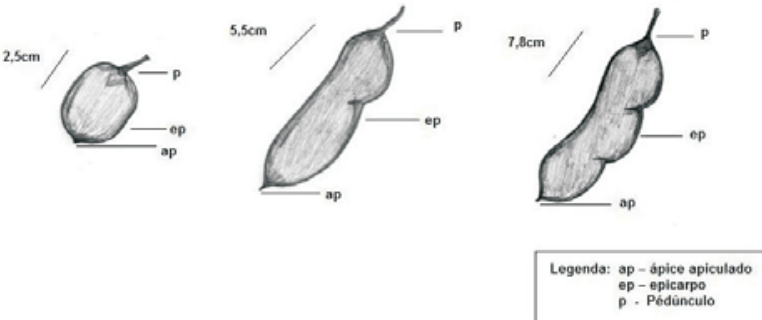

Figura 1 - Morfologia externa de fruto de Tamarindus indica L. Figure 1 - External morphology of Tamarindus indica L. fruit.

Quando polispérmico, o fruto apresenta um estrangulamento mais ou menos suave, por toda a superfície da vagem, principalmente no ponto onde fica situado o limite da semente, a qual é recoberta por um mesocarpo polposo-gelatinoso, de coloração marrom e de sabor acre.

O epicarpo desprende-se completamente da semente, deixando apenas as porções fibrosas dos bordos.

\subsection{Caracterização morfológica das sementes}

As sementes de T. indica L. são irregulares, mais ou menos retangulares, rugosas, de coloração marromescura brilhante, medindo cerca de $20 \mathrm{~mm}$ de comprimento e $12 \mathrm{~mm}$ de largura, apresentando em uma das faces um pleurograma contínuo e com aparência piriforme e, na outra, um pleurograma contínuo, tomando quase toda a sua extensão, ambos apresentando estrias retilíneas (Figura 2).

De acordo com Damião-Filho (1993) e Barroso et al. (1999), o pleurograma consiste de uma marca lateral na superfície de certas sementes, originada pela interrupção nas células da paliçada da exotesta ou, mesmo, pela diferença nas camadas externas da testa, podendo ser aberto ou fechado, sendo sua fisiologia ainda desconhecida. Nas sementes de leguminosas,

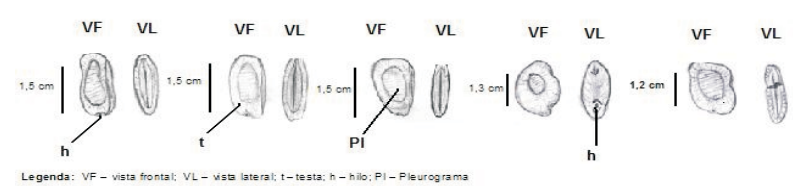

Figura 2-Diversidade morfológica das sementes de Tamarindus indica $\mathrm{L}$.

Figure 2 - Morphological diversity of Tamarindus indica L. seeds. não há pleurograma na subfamília Faboideae, ocorrendo em 67 a 70\% dos gêneros estudados de Mimosoideae e em 9 a 14\% dos gêneros estudados de Caesalpinioideae.

O seu hilo é punctiforme, cercado por pequena quantidade de arilo, e a testa possui coloração marromescura, que, geralmente em espécies leguminosas, apresenta cores marrom e preta, sendo coriácea e contendo internamente tecido mucilaginoso (entre a testa e o tegma); o tegma possui textura corticosa (GUNN, 1981).

Segundo Barroso et al. (1999), o embrião é axial, com formato reto, curvo ou circinado, com ou sem endosperma (Figura 3); é invaginado, criptorradicular, adpresso, com cotilédones crassos, faces mais ou menos convexas, de coloração amarelo-clara (bege) (Figura 3E). O eixo hipocótilo-radícula é asciforme, com plúmula contendo rudimentos bifoliolados, e a radícula é inconspícua, de extremidade pontiaguda (Figura 3F).

\subsection{Desenvolvimento pós-seminal}

A germinação da semente é do tipo epígea, e o tegumento fica aderido aos cotilédones na fase inicial do crescimento da plântula. Com a reidratação da semente e seu intumescimento, com aumento considerável de seu volume, o cotilédone de coloração verde-clara fica exposto, e a protrusão radicular (início visível da germinação) ocorre próximo ao hilo, no décimo dia após a semeadura (Figura 4A); a radícula possui coloração verde-clara, e a coifa é esbranquiçada, medindo cerca de $0,5 \mathrm{~cm}$; após 12 dias, a radícula apresenta coloração bege, com estruturas semelhantes a pelos, que posteriormente darão origem a raízes secundárias, sendo estas pouco densas e com coloração marrom-clara. Pode-se observar que o tegumento da semente ainda envolve os cotilédones (Figura 4BC).

Após 14 dias da semeadura, o tegumento começa a se desprender dos cotilédones (Figura 4C). A radícula apresenta rápido desenvolvimento, inicialmente

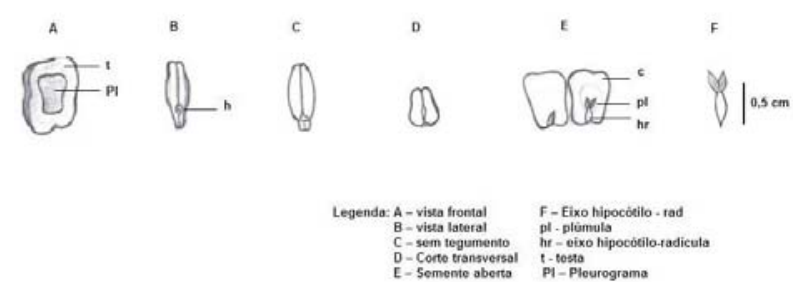

Figura 3 - Aspectos morfológicos das sementes de Tamarindus indica $\mathrm{L}$.

Figure 3-Morphological aspects of Tamarindus indica L. seeds. 


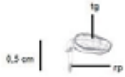
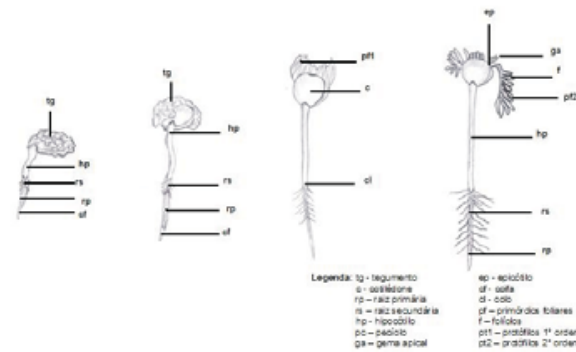

Figura 4 - Desenvolvimento pós-seminal de Tamarindus indica $\mathrm{L}$.

Figure 4-Post-seminal development of Tamarindus indica $L$.

engrossada, sofrendo afinamento com dilatação na base, sendo cilíndrica, tenra, esbranquiçada e coifa também esbranquiçada. As raízes secundárias são finas, curtas, tenras, cilíndricas e da mesma cor da raiz primária. Posteriormente, a raiz primária passa à sublenhosa, de coloração esbranquiçada a ferrugínea-clara.

Quinze dias após a semeadura, as medições da raiz principal, do hipocótilo, do epicótilo e do comprimento total foram de 9,3; 3,9; 1,6; e $15 \mathrm{~cm}$, respectivamente. O colo é bem definido pela diferença de cor entre o hipocótilo e a raiz, pela redução de diâmetro do hipocótilo e pela dilatação apresentada nessa região. O hipocótilo apresenta-se inicialmente curvado até tornar-se reto, tenro, cilíndrico, glabro, verde-claro, levemente achatado e acanalado na inserção dos cotilédones (Figura 4D).

Aos 20 dias, os cotilédones começam a se expandir (Figura 4E) até se abrirem totalmente; são viridescentes até se tornarem verde-claros na face dorsal e verdeescuros na face ventral, base invaginada e bordo inteiro; são opostos, isófilos, sésseis e nervação pouco evidente, estando inseridos num ângulo de aproximadamente $45^{\circ}$ com o eixo do epicótilo. O epicótilo é tenro, com base larga, tendo coloração verde-clara. A partir dessa fase, podem-se visualizar os protófilos de primeira ordem, que são compostos, paripenados com seis a nove pares de folíolos, opostos e pilosos; a ráquis é longo-peciolada. Os folíolos são pequenos, com a face dorsal de coloração verde-clara e a face ventral verde-escura; são opostos, ovoides, bordos contínuos, membranáceos, com nervação peninérvea, e a nervura principal é bem evidente em ambas as faces, com nervuras secundárias pouco visíveis, caracterizando as plântulas jovens. A gema apical, densamente pilosa, surge antes da completa expansão do protófilo. Nessa fase, a plântula possui cerca de
16 cm de comprimento, possuindo epicótilo, hipocótilo, raiz e os protófilos de primeira ordem expandidos, opostos e compostos.

Aos 30 dias (Figura 4F) surgem os protófilos de segunda ordem, e a plântula possui aproximadamente $23 \mathrm{~cm}$ de comprimento. Silva et al. (1991) observaram em plântulas de Erythrina velutina que o mesmo processo ocorre com elas aos 30 dias após a semeadura.

\section{CONCLUSÕES}

O fruto de Tamarindus indica L. é simples, seco, indeiscente, monocárpico, mono ou polispérmico, possuindo 1 a 11 sementes, do tipo legume bacoide.

As sementes apresentam uma região testal, bem definida, são irregulares, retangulares, rugosas, de coloração marrom-escura brilhante, medindo cerca de $15 \mathrm{~mm}$ de comprimento e $12 \mathrm{~mm}$ de largura, apresentando em ambas as faces um pleurograma. O embrião é do tipo axial, invaginado e criptorradicular, tendo germinação do tipo epígea.

\section{REFERÊNCIAS}

ARAÚJO, E. C. et al. Caracterização morfológica de frutos, sementes e plântulas de Sesbania virgata ( CAV. ) PERS. Revista Brasileira de Sementes, v.26, n.1, p.105-110, 2004.

BARRoso, G. M. Curso de identificação de sementes. Pelotas: Universidade Federal de Pelotas/CETREISUL, 1978. 36p.

BARROSO, G. M. et al. Frutos e sementes: morfologia aplicada à sistemática de dicotiledôneas. Viçosa, MG: Universidade Federal de Viçosa, 1999. 443p.

BELTRATI, C. M. Morfologia e anatomia de sementes. Rio Claro: Universidade Estadual de São Paulo, 1992. 108p. (Apostila do curso de Pós-graduação).

CHAVES, M. M. F. Descrição morfológica de sementes, de plântulas e de mudas de 10 espécies arbóreas pioneiras, na microrregião de Viçosa-MG. 1994. $108 \mathrm{f}$. Dissertação (Mestrado em Ciências Florestais) Universidade Federal de Viçosa, Viçosa, MG, 1994.

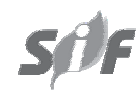

Revista Árvore, Viçosa-MG, v.34, n.6, p.1009-1015, 2010 
CUNHA, M. C. L.; FERREIRA, R. A. Aspectos morfológicos da semente e do desenvolvimento da planta jovem de Amburana cearensis (Arr. Cam.) A.C. Smith - CUMARU - Leguminosae Papilionoideae. Revista Brasileira de Sementes, v.25, n.2, p.89-96, 2003.

DAMIÃO-FILHO, C. F. Morfologia e anatomia de sementes. Jaboticabal: FCAV/ UNESP, 1993. 145p. (Apostila).

DONADIO, L. C.; NACHTIGAL, J. C.; SACRAMENTO, C. K. Frutas exóticas. Jaboticabal: FUNEP, 1988. 279p.

FARIA, M. R.; DAVIDE, A. C. Aspecto morfológico do fruto, sementes e plântulas de 4 espécies florestais nativas. Informativo ABRATES, v.3, n.3, p.113, 1993.

FELICIANO, A.L.P. Estudo da germinação de sementes e desenvolvimento da muda, acompanhado de descrições morfológicas de 10 espécies arbóreas ocorrentes no semi-árido nordestino. 1989. 114f. Dissertação (Mestrado em Ciências Florestais) - Universidade Federal de Viçosa, Viçosa, MG, 1998.

FERRI, M. G. Glossário ilustrado de botânica. São Paulo: Nobel, 1978.

FIGLIOLIA, M. B.; OLIVEIRA E. C.; PIÑARODRIGUES, F. C. M. Análise de sementes. ; In: AGUIAR, I. B.; PIÑA-RODRIGUES, F. C. M.; FIGLIOLIA, M. B. Sementes florestais tropicais. Brasília: ABRATES, 1993. p.137-174.

GUNN, C. R. Seed collecting and identification. In: KOZLOWSKI, T. T. Seed biology. New York: Academic Press, 1972. v.1. p.1-20.

GUNN, C. R. Seed topography in the Fabaceae. Seed Science \& Technology, v.9, n.3, p.737-757, 1981.

KUNiYOSHI, S. K. Morfologia da semente e da germinação de 25 espécies arbóreas de uma floresta de araucária. 1983. 233f. Dissertação (Mestrado em Ciências Florestais) - Universidade Federal do Paraná, Curitiba, 1983.
LAWREnCE, G. H. M. Taxonomia das plantas vasculares. Lisboa: Fundação Caluste Gulbekian, 1973. v.1. 296p.

MELO, M. G. G. et al. Análise morfológica de sementes, germinação e plântulas de jatobá (Hymenaea intermedia Ducke var. adenotricha (Ducke) Lee \& Lang.) (Leguminosaecaesalpinioideae). Acta Amazônica, v.34, n.1, p.9-14, 2004.

OLIVEIRA, E. C. Morfologia de plântulas florestais. In: AGUIAR, I. B.; PIÑA-RODRIGUES, F. C. M.; FIGLIOLA, M. B. Sementes florestais tropicais. Brasília: ABRATES, 1993. p.175-214.

OLIVEIRA, A. K. M.; SCHLEDER, E. D.; FAVERO, S. Caracterização morfológica, viabilidade e vigor de sementes de Tabebuia aurea (Silva Manso) Benth. \& Hook. f. ex. S. Moore. Revista Árvore, v.30, n.1, p.25-32, 2006.

PINHEIRO, A. L. et al. Estudos dendrológicos com vistas à regeneração natural de Meliaceae na microrregião de Viçosa. I. Identificação e descrição de dez espécies. Revista Árvore, v.13, n.1, p.1-66, 1989.

RODERJAN, C. V. Morfologia do estádio juvenil de 24 espécies arbóreas de uma floresta com araucária. 1983. $148 \mathrm{f}$. (Dissertação (Mestrado em...) - Universidade Federal do Paraná, Curitiba, 1983.

RODRIGUES, F. C. M. P.; ARAKI, S. M. N. Formação da semente. In: PIÑA-RODRIGUES, F. C. M. Manual de análise de sementes florestais. Campinas: Fundação Cargil, 1988. 100p.

RODRIGUES, R. S.; TOZZI, A. M. G. A. Morfologia de plântulas de cinco leguminosas genistóides arbóreas do Brasil (LeguminosaePapilionoideae). Acta Botanica Brasílica, v.21, n.3, p.599-607, 2007.

SALLES, H. G. Expressão morfológica de sementes e plântulas I. Cephalocereus fluminensis (Miq.) Britton e Rose (Cactaceae). Revista Brasileira de Sementes, v.9, n.1, p.73-81, 1987. 
SILVA, L. M. M.; MATOS, V. P. Morfologia da semente e da germinação de Erythrina velutina Willd. Revista Árvore, v.15, n.2, p.137-143, 1991.

SILVA, L. M. M.; MATOS, V. P.; LIMA, A. A. Morfologia do fruto, da semente e da germinação de espinheiro (Machaerium angustifolium Mart.)

- Leguminosae. Informativo ABRATES, v.3, n.3, p.113, 1993.

SILVA, G. G. et al. Caracterização física e química de tamarindo (Tamarindus indica l) em diferentes estádios de maturação. Revista Brasileira de Fruticultura, v.22, n.2, p.291-293, 2000.
SOUZA, L. A.; OLIVEIRA, J. H. G. Morfologia e anatomia das plântulas de Tabebuia avellanedae Lor. ex Griseb e T. chrysotricha (Mart. ex Dc.) Standl. (Bignoniaceae). Acta Scientiarum. Biological Sciences, v.26, n.2, p.217-226, 2004.

VIDAL, W. N.; VIDAL, M. R. R. Botânica: Organografia. 3.ed. Viçosa, MG: Universidade Federal de Viçosa, 1984. 114p.

VIDAL, V. N. Considerações sobre as sâmaras que têm ala paranuclear. Rodriguesia, v.30, n.47, p.109-168, 1978. 